\title{
A genetic and molecular model for flower development in Arabidopsis
}

\section{thaliana}

\author{
ELLIOT M. MEYEROWITZ*, JOHN L. BOWMAN, LAURA L. BROCKMAN, GARY N. DREWS, \\ THOMAS JACK, LESLIE E. SIEBURTH and DETLEF WEIGEL \\ Division of Biology 156-29, California Institute of Technology, Pasadena, Callfornia 91125, USA \\ * Corresponding author
}

\section{Summary}

Cells in developing organisms do not only differentiate, they differentiate in defined patterns. A striking example is the differentiation of flowers, which in most plant families consist of four types of organs: sepals, petals, stamens and carpels, each composed of characteristic cell types. In the families of flowering plants in which these organs occur, they are patterned with the sepals in the outermost whorl or whorls of the flower, with the petals next closest to the center, the stamens even closer to the center, and the carpels central. In each species of flowering plant the disposition and number (or range of numbers) of these organs is also specified, and the floral 'formula' is repeated in each of the flowers on each individual plant of the species. We do not know how cells in developing plants determine their position, and in response to this determination differentiate to the cell types appropriate for that position. While there have been a number of speculative proposals for the mechanism of organ specification in flowers (Goethe, 1790; Goebel, 1900; Heslop-Harrison, 1964; Green, 1988), recent genetic evidence is inconsistent with all of them, at least in the forms in which they were originally presented (Bowman et al. 1989; Meyerowitz et al. 1989). We describe here a preliminary model, based on experiments with Arabidopsis thaliana. The model is by and large consistent with existing evidence, and has predicted the results of a number of genetic and molecular experiments that have been recently performed.

Key words: Arabidopsis thaliana, pattern formation, floral mutants.

\section{Processes in flower development}

From many descriptions of flower development (Payer, 1857; Sattler, 1973), we can divide the developmental processes that lead to flowers into four successive stages. The first is floral induction. This is the process by which the shoot apical meristem, which is the set of dividing cells that gives rise to most of the plant parts that are above the roots, decides that it is time to stop making leaves, and to start making flowers (Bernier, 1988). Induction is effected in different ways in different plants; in Arabidopsis a combination of internal and environmental signals, including age of the plant, its nutritional state, day length, and in some strains temperature, determines that the apical meristem will change its fate from vegetative to floral. Once this has happened the second stage of flower development begins. This is the production of individual flowers on the flanks of the shoot apical meristem. These floral primordia arise, by patterned cell divisions, in a defined temporal and spatial pattern (Fig. 1A). The third stage is the formation of organ primordia on each flower primordium. The wild-type Arabidopsis flower contains 15 separate organs: four sepals, four petals, six pollen-bearing stamens, and a pistil (Fig. 1). In Arabidopsis, the third stage of floral development is thus the formation of 15 undifferentiated organ primordia (Fig. 1B,C), at stereotyped positions within the flower primordium. These organ primordia are at this time not only undifferentiated, but are also not irreversibly determined, so that their fates are as yet either partly or completely unspecified (Bowman et al. 1989). The final stage of flower development is the specification of the fates of the organ primordia, and their consequent differentiation into organs appropriate for their positions (Fig. 1D). Each organ is composed of a small number of defined cell types, some of which (e.g. pollen sperm cells) are organ-specific, and some of which (e.g. guard cells) are found in several kinds of organs. Detailed descriptions of flower development in Arabidopsis thaliana are available (Hill and Lord, 1989; Smyth et al. 1990).

That each of these stages of flower development is to some degree a separate process, effected by a different 

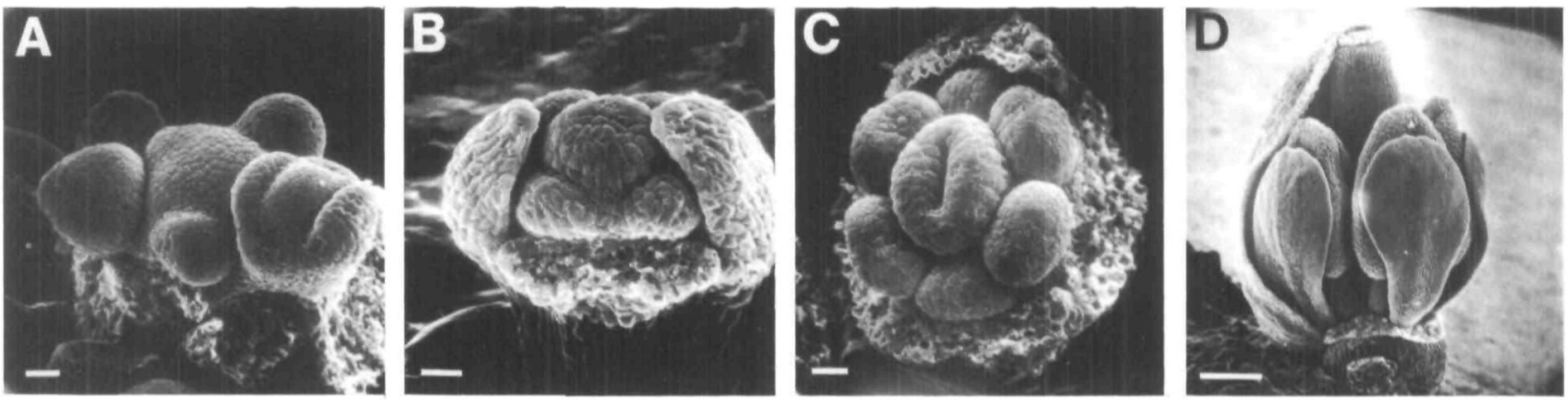

Fig. 1. Scanning electron microscope views of the development of wild-type Arabidopsis flowers. (A) A florally-induced shoot apıcal meristem (inflorescence meristem) surrounded by a series of flower primordia. The developmentally most advanced flower primordium is at the right, and is showing the earliest stages of sepal development (stage 3). (B) An individual flower primordium at stage 6 , when organ primordia have formed, but are not yet fully specified. Two sepals have been removed to reveal the underlying inner whorl primordia. (C) Another developing flower. at stagc 7, with all of the sepals removed to show the first signs of organ-specific differentiation of the six third whorl organs (which are becoming stamens) and of the fourth-whorl ovary. (D) Developing flower at stage 11, when the organ-specific differentiation of the epidermal cells of each organ type is evident. Sepals have been removed to reveal the inner organs. The bars in panels $\mathrm{A}, \mathrm{B}$ and $\mathrm{C}$ represent $10 \mu \mathrm{m}$, that in panel D $100 \mu \mathrm{m}$.

group of regulatory genes in Arabidopsis, is indicated by the existence of many mutations that affect only one or only a subset of the stages. That these processes are interrelated is equally demonstrated by the fact that many mutations affect more than one of them. The mutations that interfere with the fourth stage are homeotic: they cause normal organs to develop in abnormal places (Pruitt et al. 1987; Meyerowitz et al. 1989). Some of these mutants are normal up to the time when the undifferentiated organ primordia are formed, and these primordia generally appear in their wild-type numbers and places. Other mutants affect organ number and organ position as well as organ identity.

There is much more known about the fourth stage in flower development than about the others: we have done a series of genetic experiments that have led us to a working hypothesis for the way in which three classes of homeotic genes specify organ identity in each floral whorl (Bowman et al. 1989; Bowman et al. 1991). This model does not. however, explain the phenotypes of the homeotic mutants that relate to organ number and position. Nonetheless, the model has correctly predicted patterns of organ identity in doubly and triply mutant strains, and predicts both the pattern of expression of the RNA of one of the homeotic genes, and the changes in that pattern that result from mutations in one of the other homeotic genes.

\section{A genetic model for organ identity in flower development}

Wild-type Arabudopsis flowers have four concentric sets of organs, which consist of (from the outside of the flower) four sepals, four petals, six stamens, and an ovary (Figs 2A and 3). Mutations that alter this pattern were first recognized in Arabidopsis by Braun (1873), who recognized a homeotic phenotype in a wild population of plants in Berlin. To begin our genetic and molecular characterization of Arabidopsis flower devel- opment, we collected from others, and produced ourselves, a large series of mutations (induced by ethyl methanesulfonate or X-rays) with abnormal floral phenotypes. As described above, these mutations fall into several classes, each apparently affecting one or more processes in flower development. We have concentrated on the homeotic mutations that affect the fourth stage in flower development, including the process by which unspecified organ primordia learn their fate. Of the mutations initially screened, many gave clear, reproducible homeotic phenotypes. Complementation analysis (by us and others) has shown that most of these fall into four complementation groups, and thus represent four genetic loci with major effects on organ type specification (Pruitt et al. 1987; Meyerowitz, 1987; Komaki et al. 1988; Bowman et al. 1989; Kunst et al. 1989; Meyerowitz et al. 1989: Yanofsky et al. 1990; Bowman et al. 1991).

\section{Four mutations in three classes}

These loci are agamous (ag), at position $37.6 \mathrm{cM}$ on the fourth chromosome in the morphological marker map of Arabidopsis (Koornneef, 1989); apetala2 (ap2) at 4-63.5; pistillata (pi) at 5-23.6; and aperala3 (ap3) at 3-73.9. All of the mutations at these loci are recessive (except for one semidominant ap2 allele which we recently obtained). Fig. 3 shows the map positions of these four loci, and schematically represents the phenotypes of one or more mutant alleles of each of the genes. To describe the phenotypes we will use the term whorl to mean a region of the flower or flower primordium (and not the collection of organs found in that region). The first whorl is the outer ring of tissue, from which the sepals arise in wild-type flowers. The second whorl is the next inner concentric ring, from which petals normally arise. The third whorl is the ring from which stamens develop in wild type, and the fourth whorl is the bull's-eye. It is the normal location of the ovary.

Each of these mutations affects the organs of two 

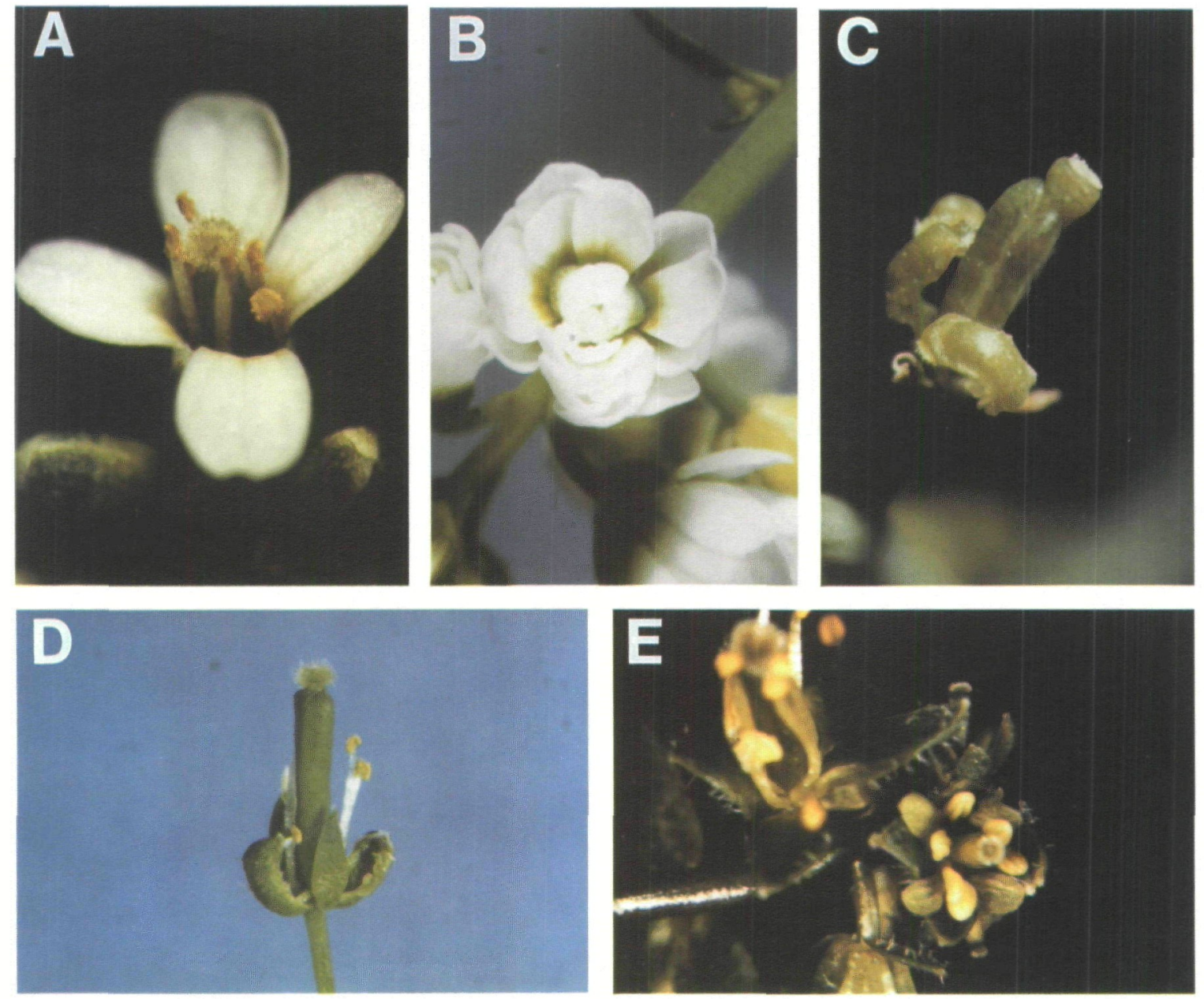

Fig. 2. Mature Arabidopsis flowers. (A) Wild type, showing the four petals, six stamens, and ovary. (B) agamous-3 homozygote, showing the extra petals and sepals, as well as the absence of stamens and ovary. (C) apetala3-1 homozygote, with the organs of the outer two whorls removed to show the third whorl organs, which develop as carpels rather than stamens, as in wild type. (D) apetala2-2/apetala2-1 heterozygous flower, showing first whorl carpels, absence of second whorl organs, and normal organ identity (though not number) in the third whorl. The fourth whorl is normal. (E) apetala2-1 homozygous flowers, showing first whorl leaves and second whorl stamens. The third and fourth whorl organs are normal. 

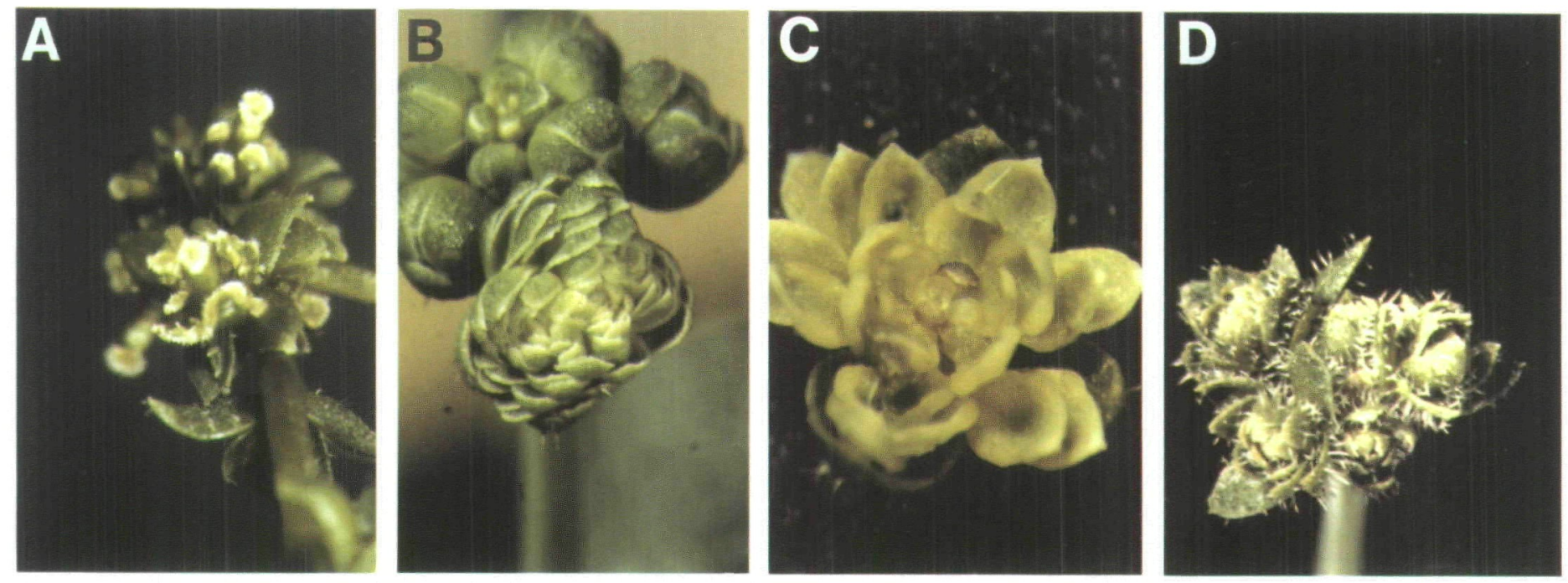

Fig. 5. Flowers of doubly and triply mutant strains. (A) Flowers homozygous for both ap2-l and ap3-1. All organs are carpelloid. (B) Flowers homozygous for both ap3-l and ag-1. All floral organs are sepals. (C) Flower homozygous for ap2-l as well as ag-l. showing that the whorl 1 and 4 organs are leaves, and the whorl 2 and 3 organs are intermediate between petals and stamens.

(D) Triply mutant inflorescence. homozygous for the three mutations ap $2-1$, ag- 1 . and pi-l. In each flower, all of the floral organs have developed as leaves.

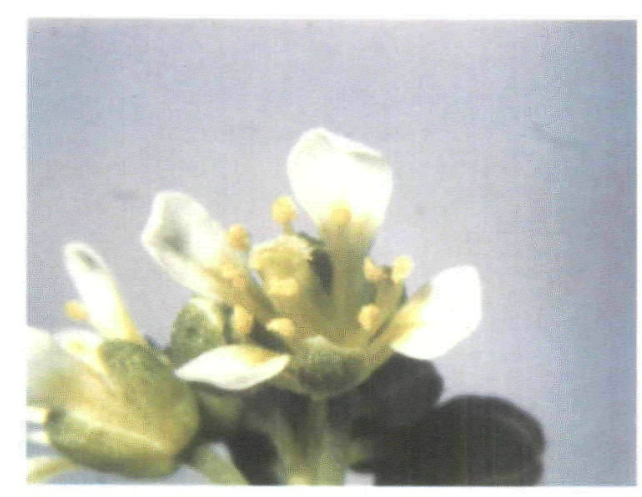

Fig. 6. Flower of a plant homozygous for superman- $I$. Note the four sepals. four petals. 10 stamens. and reduced ovary. 
adjacent whorls. The agamous mutations (of which three alleles have been studied, i.e. $a g-1, a g-2$ and $a g-3$ ) affect only whorls three and four. The six organs of whorl three develop as petals rather than stamens, and the whorl four primordium forms four sepals, inside of which are additional whorls of petals and sepals. Thus, if the normal pattern of sepals, petals, stamens, ovary is called an $\mathrm{ABCD}$ pattern, agamous mutants have an ABBA(BBABBA...) pattern (Fig. 2B). We have extensively studied three $p i$ alleles, $p i-1, p i-2$ and $p i-3$ (Bowman et al. 1989; Bowman et al. 1991) and two ap3 alleles (one is described by Bowman et al. 1989), and both $p i$ and ap3 affect whorls two and three only, having essentially the same effects (except for some details of the pi- 1 third whorl, where the organ primordia do not form normally). Whorl two contains four sepals rather than the wild-type four petals, and instead of the wildtype pattern of six third whorl stamens, the mutant whorl three consists of six carpels (the subunit of the ovary; the normal Arabidopsis ovary consists of two carpels). These mutations thus have the phenotype AADD (Fig. 2C). Apetala2 mutants, four alleles of which have been studied in our laboratory (Pruitt et al. 1987; Bowman et al. 1989; Bowman et al. 1991), and five more by others (Komaki et al. 1988; Kunst et al. 1989), affect organ identity in whorls one and two. In most alleles (the single exception will be explained below) the organs of the first whorl are carpels, and the second whorl consists of four (or sometimes fewer) stamens in the places normally occupied by the four petals. Most alleles also have effects on organ number in the first, second and third whorls, and on the position of initiation of organ primordia in whorls 1, 2 and 3 . Since we have only succeeded in producing a model for organ identity, and not for organ number, we will for present purposes consider the relevant pattern of most alleles to be DCCD (Fig. 2D). Discussion of the effects of AP2 on organ number and position will be reserved for later.

\section{A working hypothesis, in the form of a model}

We have proposed a simple model to explain the wildtype functions of the homeotic genes (Bowman et al. 1989; Bowman et al. 1991). It proposes that these four genes fall into three classes, each class affecting a different pair of whorls. APETALA2 is the only known gene in the first class, which affects whorls 1 and $2 ; A P 3$ and $P I$ constitute the presently-known second class, with effects in whorls 2 and 3 ; and $A G$ is the only known member of the final class, which affects whorls 3 and 4 . Each class of genes is expressed in the developing flower in those whorls affected in the mutants. Whorl one is thus characterized by expression of $A P 2$; whorl two by the combination $A P 2, P I$ and $A P 3$; whorl three by the combination $A G, P I$ and $A P 3$; and whorl four by the expression of $A G$. Each of the products of these genes has as its function the induction of expression of a series of downstream genes, the expression of which

\section{LINKAGE GROUP}

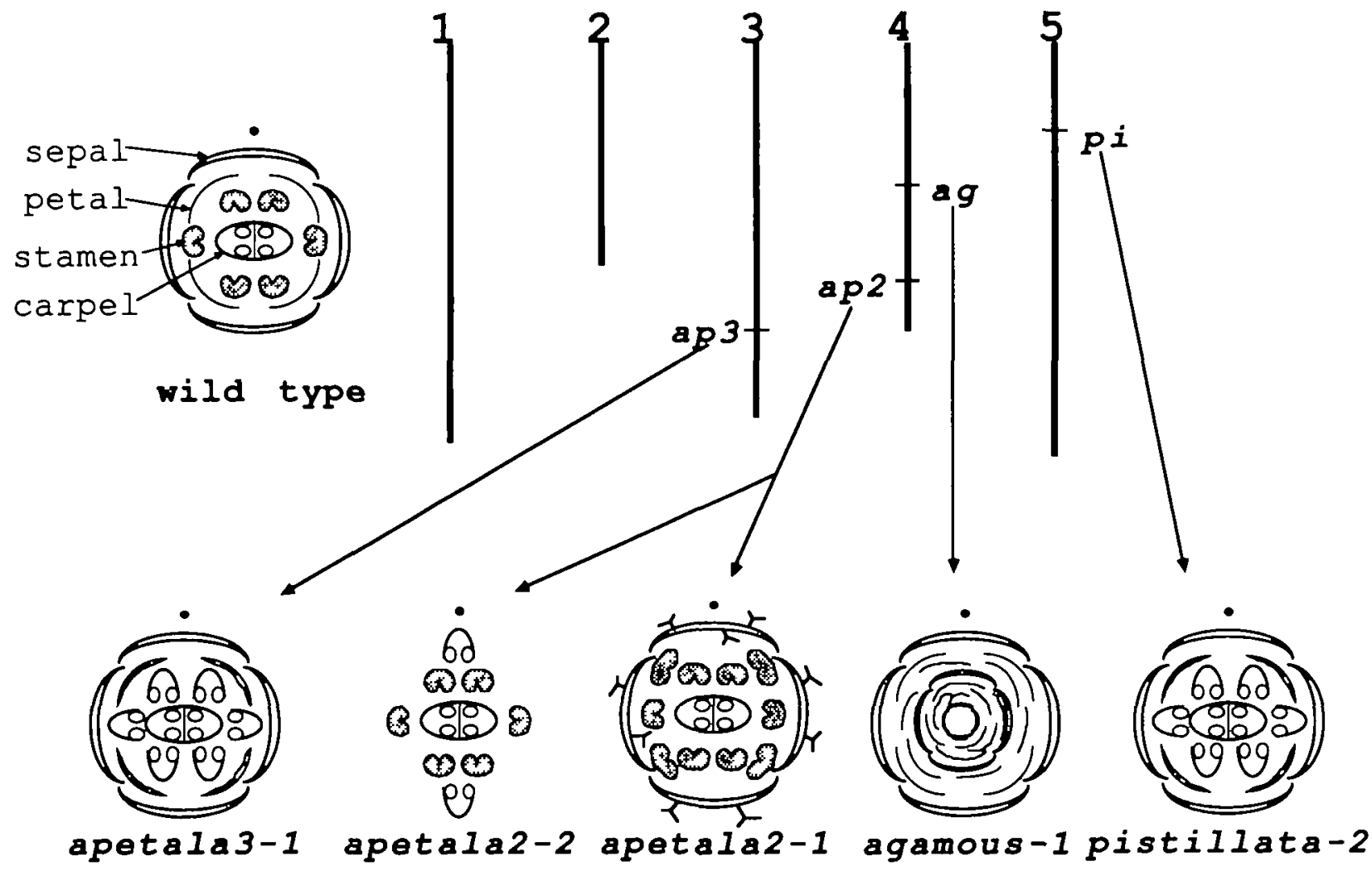

Fig. 3. Schematic representation of the phenotypes of some mutant alleles of the four best-studied homeotic genes. The structure of a wild-type Arabidopsis flower, and the genetic map positions of the homeotic genes, are also depicted. 
controls or constitutes the differentiation of specific floral organs. When $A P 2$ (and any other genes in the same class, if there are any) is expressed alone in any organ primordium, the primordium differentiates to a sepal. The combination of two classes of genes, $A P 2$ plus $P I / A P 3$, directs a primordium to differentiate to a petal; the third-whorl combination $P I / A P 3$ plus $A G$ directs stamen differentiation. If only $A G$ (and other genes in the same class, if they exist) is expressed, the primordium differentiates to a carpel. Thus, these genes are expected to begin to be active before any organ differentiation, and to direct the fate which organ primordia will adopt.

One further aspect is needed for the model to explain the mutant phenotypes. We propose an interaction between the whorl $1 / 2(A P 2)$ and whorl $3 / 4(A G)$ genes. In addition to its action on downstream genes, $A P 2$ represses $A G$ expression in whorls 1 and 2 . In addition to its action on downstream genes, $A G$ represses expression of $A P 2$ in whorls 3 and 4 .

The model now explains the single mutant phenotypes. Fig. 4 shows, at the top, the wild-type overlapping patterns of expression of these genes in the different whorls, as proposed by the model. Beneath this is shown the expected pattern of expression in an ap 2 mutant. Since the wild-type $A P 2$ product is absent. $A G$ is expressed in all four whorls. The expression of the $P I$ and $A P 3$ genes is unaffected. Whorl 1 organs thus differentiate into carpels, as directed by $A G$, whorl 2 and 3 organs into stamens, as directed by the $A G$ and $P I$ plus $A P 3$ combination, and whorl four is normal. The effect of ag mutations is shown below: the pattern of expression of regulatory genes is normal in whorls 1 and 2 . The absence of wild-type $A G$ product allows $A P 2$ to express in whorls 3 and 4 , and dictates that the order of organs thus be sepals, petals, petals, sepals. The existence of the further whorls that are present inside whorl 4 in ag mutants is not specifically predicted by the model (in Fig. 4 this is noted by the asterisk), and indicates that one of the functions of $A G$ is to turn off downstream genes that allow continued cell division in the center of the developing flower. There is additional evidence for this $A G$ function, which will be described below. The phenotype of pi or ap3 mutants and its origin is also shown in Fig. 4: in the absence of the function provided by the activity of these genes, the first two whorls express only $A P 2$ and differentiate to sepals, while the third and fourth whorl organs express only $A G$ and differentiate to carpels.

\section{Genetic tests of the model}

The first test we have applied to see if this model can actually predict anything other than the original mutant phenotypes (on which, after all, it is based) is to predict the phenotypes of double and triple mutant combinations, and then to test the predictions by making plants homozygous for all possible pairs of mutations. All of the double and triple mutant combinations agree with the predictions of the model (Fig. 5, Bowman et al. 1989; Bowman et al. 1991).

If the double mutant ap 2 ap 3 (or ap 2 pi) is made, it is expected that all whorls will express only $A G$, and that all organ primordia will differentiate to carpels. This is indeed what is seen in the double mutant (Fig. 5A). An ap3 (or pi) ag double mutant retains only the $A P 2$ function, which is predicted to be expressed in all four whorls. This is expected to convert all floral organs to sepals. The doubly mutant plants do in fact give the expected pattern of all organs developing as sepals, and in addition, because of the indeterminate growth of ag

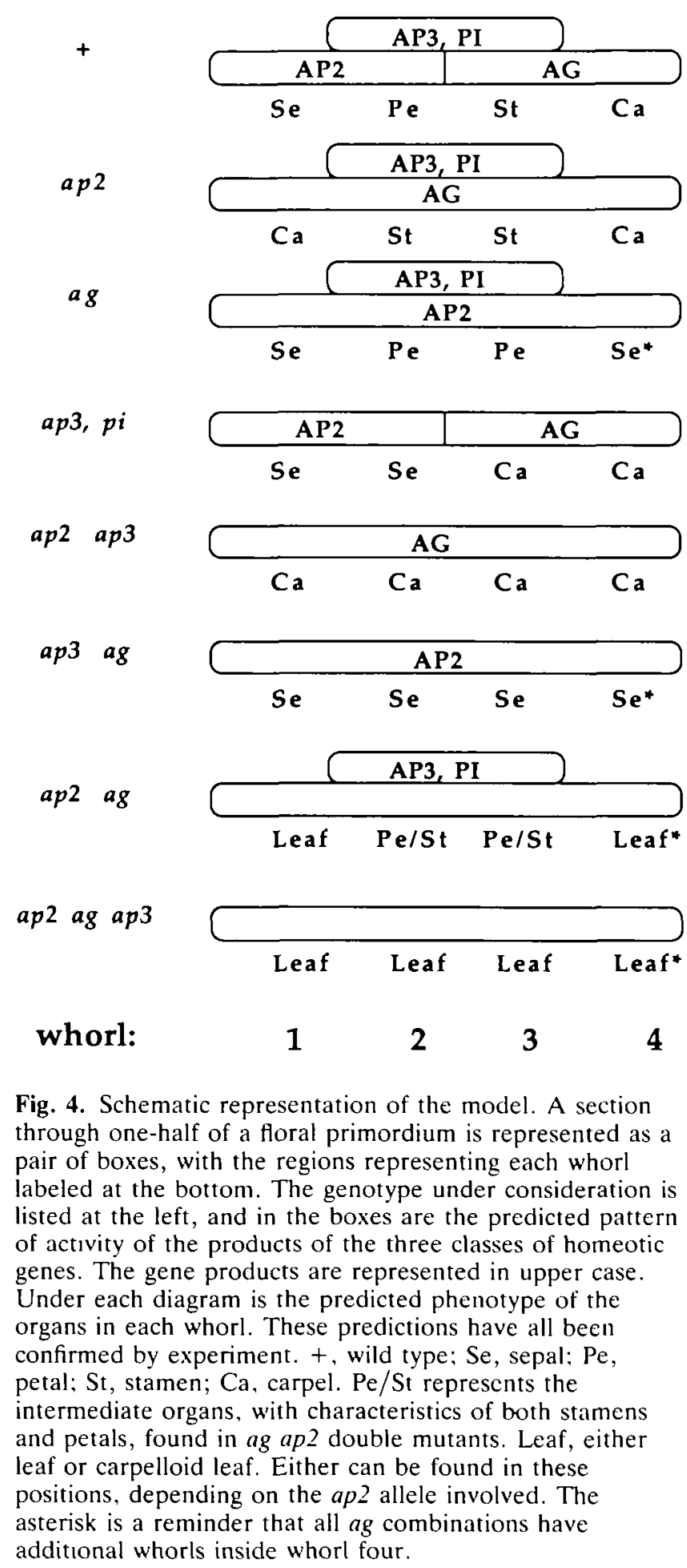


flowers, the double mutants have many more than four whorls, see Fig. 5B.

The ap2 ag double mutant prediction is the most important. The model (see Fig. 4) predicts that whorls 1 and 4 will have no expression of any of the classes of homeotic genes, and thus if the three known classes of homeotic gene are necessary for floral organ development, the whorl 1 and 4 primordia will differentiate into organs unlike any normally seen in flowers. In fact, by many criteria, the whorl 1 and 4 organs in the mutant are leaves (stellate trichomes, stipules, shape, pattern of guard cells, appearance of spongy mesophyll, leaf and not sepal senescence pattern) or carpelloid leaves. This implies that the three classes of genes are almost sufficient to explain floral organ differentiation (an asyet unknown class may contribute the carpelloid aspect of these organs). The phenotype of the whorl 2 and 3 organs in the double mutant is expected to be intermediate between that of petals and stamens, since the ap3/pi class of genes is expressed, giving these organs the potential to develop as either petals or stamens, but the gene activities that would decide between these two fates are absent. The double mutant phenotype in these whorls is in accord with expectation (Fig. $5 \mathrm{C}$ ). The phenotype demonstrates the $A P 2-A G$ interaction that the model postulates: in ag mutants alone there are no whorl 1 or 2 effects, but adding ag to an ap2 mutant does create new whorl 1 and whorl 2 phenotypes. Likewise, ap2 normally has no effect on organ identity in whorl 3 or whorl 4 , but it does have such an effect in the absence of wild-type $A G$ product.

The triple mutant combinations ap 2 pi ag and ap2 ap 3 ag should reveal the ground state in every whorl, and should not contain any floral organs, only vegetative, or close to vegetative, ones. This does indeed occur, and in the triple mutants each organ in each whorl is converted to leaves, or slightly carpelloid leaves. It is worth noting that it is now just past the 200th anniversary of Goethe's statements that all floral organs are derived from the basic ground state of leaf, by the action of different qualities of sap on the basic organ (Goethe, 1790).

There are several observations that were quite puzzling before the flower development model was conceived, but which are now seen to fit the model very well. The best example is that of the 'weak' ap2 allele, ap2-1 (Fig. 2E). Unlike the other eight described alleles of $a p 2$, which have first whorl carpels, ap2-1 when grown at $25^{\circ} \mathrm{C}$ has leaves in the first whorl. All second whorl ap 2 organs are stamens, or are staminoid. We have called this allele 'weak' because its phenotype seems to be that of a partial loss of $A P 2$ product function. At low temperatures $\left(16^{\circ} \mathrm{C}\right)$ it is very close to wild type, with leafy first whorl organs, but petals in the second whorl. At intermediate temperatures $\left(25^{\circ} \mathrm{C}\right)$ it is less normal, with first whorl leaves and second whorl stamens. At $29^{\circ} \mathrm{C}$ this mutant has carpelloid leaves in the first whorl, and stamens in the second whorl. (For a more detailed description, see Bowman et al. 1989.) Thus, the intermediate leaf phenotype in the first whorl appears on a graded path of loss of function. The model accounts for this nicely: it predicts two functions for the wild-type $A P 2$ product. One is repression of $A G$ activity in whorls 1 and 2 , the other is induction of a series of downstream genes, the activity of which produces the differentiation of outer whorl organs. If, in the first whorl, the first activity is present and the second absent, then none of the homeotic gene activities will be expressed there, and we expect (and get) leaves. When both activities are absent, as in the strong ap 2 mutants, carpels form in the first whorl.

\section{A working genetic model is insufficient}

Our model is very effective at explaining and predicting genetic results as far as regulation of organ identity is concerned. The model, however, makes no explicit predictions about the actual mechanisms involved in the postulated activities of the homeotic genes, other than that they regulate each other's activities, and activate or repress downstream genes. It does not predict the nature of the downstream genes on which the homeotic genes act, and it does not indicate the nature of the early pattern of gene inducers that exists prior to expression of the homeotic genes, and to which they respond by turning on in pairs of adjacent whorls. It says nothing of the detailed patterns of different cell types which actually constitute the floral organs; it treats each organ as a homogeneous structure, not a mosaic of different cell types, arrayed in stereotyped patterns. The model may also not be unique. Though we have not thought of any other model as effective in predicting genetic results, there may be one. Thus, we need to know the structure, activity, expression pattern and nature of the products of the genes whose activities are only described in a very general fashion by our current working model. The model needs to be tested at the molecular level, and if the tests confirm it, it needs to be refined. The tests in progress involve cloning the homeotic genes, and analysis of their expression and of their products, and of the function of these products.

\section{The molecular cloning of the Agamous locus}

The molecular tests of the genetic model have started with the molecular cloning of $A G$ (Yanofsky et al. 1990). In the course of a large series of Arabidopsis transformation experiments, whose goal was T-DNA tagging of Arabidopsis genes, Dr K. Feldmann obtained what appeared to be (and on complementation testing was) a new agamous allele (Feldmann et al. 1989), and made it available to us. Since at that time we had only carefully characterized one EMS-induced allele, ag- 1 , we called the new one ag-2. Since it arose in a transformation experiment, it seemed possible that the new mutation might be due to the chance insertion of the introduced DNA into the $A G$ locus. We cloned the DNA next to the insertion point of the introduced DNA, and RFLP (restriction fragment length polymorphism) mapped it (using the markers and methods described in Chang et al. 1988). The map positions of the flanking DNA and agamous were identical, and on direct cosegregation analysis, the cloned DNA and the ag-1 mutation were not separated. The cloned fragment 
from the mutant was used as a probe to isolate cosmid clones from wild-type plants, and one of these clones was transformed into ag-2 mutant plants using Agrobacterium tumefaciens T-DNA insertion via leaf discs. The regenerated plants had wild-type flowers. This showed that the cloned DNA contains the $A G$ gene

To find which of the transcripts coded in the cosmid corresponds to the $A G$ gene, a series of wild-type cDNA clones coded by the cloned genomic DNA was obtained. The introduced T-DNA in the ag-2 strain, which is a $35 \mathrm{~kb}$ DNA insertion, was found to be in the middle of a large intron of a gene with (at least) 9 exons and 8 introns, which codes for a $1.1 \mathrm{~kb}$ RNA that is expressed in inflorescences. To be certain that this was the $A G$ gene, the wild-type gene and the ag- $I$ mutant version of the gene were sequenced. The ag- 1 mutant had been induced in the Landsberg erecta strain, the same strain from which the wild-type gene used for the initial DNA sequencing was cloned. The sequence of the $a g-1$ DNA showed a single nucleotide change from wild-type, in the same gene that was tagged in ag-2. The change is a $\mathrm{G}$ to A transition at the acceptor site for the fourth intron, a change that presumably prevents proper splicing. Thus, by criteria of complementation and mutant sequencing, the cloned gene is $A G A$ MOUS.

Comparison of genomic and cDNA sequences has allowed the gene structure to be determined. The only unusual feature is that the second intron is 2,985 bases, the largest identified plant intron. There are also two very small exons, each 42 bases. These are the sixth and seventh exons (of the gene as so far understood: the $5^{\prime}$ end is not yet in hand, and may be in an as-yetundiscovered, additional exon). The spliced RNA, as indicated by the cDNA clone sequences, contains a single long open reading frame of, so far, 285 amino acids. The deduced amino acid sequence of the coded protein is revealing; the second exon of the $A G$ gene shows a striking homology with the DNA binding (and protein dimerization) domain of two previously identified DNA-binding transcription factors. These are serum response factor (SRF) of vertebrates, which is a transcriptional regulator of the $c$-fos oncogene in humans, and of a cytoskeletal actin gene in Xenopus (Norman et al. 1988; Boxer et al. 1989), and PRTF, the product of the Saccharomyces MCMl gene, a key transcriptional regulator of mating-type specific genes (Passmore et al. 1989; Jarvis et al. 1989; Herskowitz, 1990). The region of similarity between the three proteins spans 58 amino acids, of which 32 are identical (with no gaps introduced) between the Arabidopsis and yeast genes, and 25 are identical between the human and Arabidopsis genes. The Arabidopsis gene shows identical or conserved amino acids at more than $80 \%$ of the positions in this 58 amino acid region, when compared to either of the other genes. The sequence outside this DNA binding (and protein dimerization) region is not similar for any pairwise comparison of yeast, human and plant genes. Details of the cloning of AGAMOUS, and of the sequencing results, are described by Yanofsky et al. (1990).

\section{Molecular tests of the working model}

The sequence of $A G$ is therefore consistent with the genetic model of its action. It is postulated that $A G$ regulates $A P 2$ expression, and that it acts to regulate a series of downstream genes as well. A transcription factor could certainly act this way, though of course much more will have to be known about the specific interactions of $A G$ and other genes and their products before the function and role of the $A G$ protein are understood. Many tests of the working model have been made possible by obtaining cloned copies of the $A G$ gene, and some tests have already been started.

The first is RNA blot hybridization to determine the specificity of $A G$ RNA expression. Whole plants were taken prior to flowering, and $\operatorname{poly}(\mathrm{A})^{+}$RNA made. $\operatorname{Poly}(\mathrm{A})^{+}$RNA was also extracted from flowering stems which had their apical inflorescence removed. In addition, both poly $(\mathrm{A})^{+}$RNA and polysomal poly $(\mathrm{A})^{+}$ RNA were made from young inflorescences. These were subjected to agarose gel electrophoresis, and the gel pattern blotted to a nylon membrane. $A G$ cDNA probes were hybridized to this blot at high stringency, and a $1.1 \mathrm{~kb}$ RNA identified in both inflorescence samples. Quantitative analysis of the blot indicates that the RNA is present as one part in $10^{4}$ of poly $(\mathrm{A})^{+}$or polysomal RNA from whole inflorescences. The RNA was also identified in the pre-flowering plant RNA and the floral stem lanes, but at a level about 100 times less than in the inflorescence lanes. Since pre-flowering rosette leaves each have small, developmentally arrested floral buds in their axils, and since the cauline (stem) leaves of the flowering stem also have arrested buds in their axils, it is possible that the signal from these lanes is due to $A G$ expression in early floral primordia, and that $A G$ is exclusively expressed in developing flowers. In any event, most if not all of the expression of the gene is confined to developing flowers.

A more refined examination of the time and place of $A G$ expression has been started (Yanofsky et al. 1990; G. N. Drews, J. L. Bowman and E. M. Meyerowitz, submitted). An RNA transcript of a portion of one of the $A G$ cDNAs (chosen so as not to cross-hybridize with any of the $A G$ homologues, see below) was labeled with ${ }^{35} \mathrm{~S}$ and hybridized in situ to tissue sections of floral apices. After autoradiography, the pattern of $A G$ expression was examined. So far, the expression appears to be confined to developing flowers, and no expression was seen either in leaves, stems, or in the inflorescence (shoot apical) meristem. The expression starts at the time the sepal primordia are first beginning to form (stage 3, Smyth et al. 1990), and before the primordia of other organs appear. Expression is in the central part of the undifferentiated floral primordium, where whorl 3 and 4 organ primordia will later arise. $A G$ RNA continues to be present when organ primordia form in whorls 2, 3 and 4 , and the autoradiographic signal is confined to the stamen and ovary primordia. The RNA remains present throughout flower development, with expression in all of the cells of 
the developing stamen except for pollen mother cells and pollen, and in almost all cells of the ovary. The RNA signal is especially strong in stigmatic tissue and in developing ovules (though apparently not over the embryo sac).

The early expression pattern is exactly that predicted by the model, a very encouraging result. One additional preliminary set of in situ hybridizations has been done, and these are a key test of the working model. $A G$ probe has been hybridized to sections of $a p 2-1$ and ap 2-2 floral apices (G. N. Drews, J. L. Bowman and E. $M$. Meyerowitz, submitted). $A G$ expression expands to include all whorls in an ap2-2 background, and in whorls 2,3 and 4 , but not (or only slightly) in 1, in the ap2-1 mutant. This is a striking molecular confirmation of the genetic model, which predicted exactly this interaction of the different $A P 2$ alleles and the activity of the $A G$ gene (or its product). It is already clear from the in situ experiments that the expression pattern of $A G$ is more complex than that predicted by the model; it is expressed in many differentiated cell types in late flower development, and there is at least a hint of different strengths of expression in different flower regions. There is also apparent down-regulation in the gametophytes of both sexes. Molecular studies of $A G$ are thus certain to lead to refinements of the model, and to begin to take the general and idealized model closer to reality.

\section{The Agamous gene family}

One final set of preliminary studies is that of $A G$ homologues in the Arabidopsis genome. Low stringency genomic blots show a series of about 15 bands in the Arabidopsis thaliana genome that cross-hybridize with $A G$ cDNA probes, and low-stringency hybridizations with synthetic oligonucleotides representing portions of $A G$ (particularly the SRF-homologous region) show additional bands. We have so far cloned at least a dozen of these genes, and have sequence information on six of them (Ma et al. 1991). Each of these six genomic regions is expressed as an RNA in inflorescences, which were the source of the RNA for the cDNA library. The sequence analysis shows that the coded proteins are related to $A G$ most strongly in the SRF-homologous region, though homology extends beyond this. All six of these clones have been analyzed in RNA blots, and five of the six appear to be specific to floral apices and stems. The sixth is expressed in vegetative tissues as well as in flowers. There is thus an intimation that this gene family includes many genes involved in flower development, and that the region through which they appear to be most related, the part with homology to known DNA-binding regions in other kingdoms, may be some sort of 'floreo' box, much as the unrelated Drosophila homeobox is a DNA binding motif shared by a large fraction of the genes involved in pattern formation processes in fly embryos. This possibility is strengthened by the report that a homeotic gene from Antirrhinum (the only plant homeotic gene other than $A G$ which has been cloned and for which a sequence is published) has AGAMOUS homology in the putative DNA binding site region. This gene, $D E F$ $A$, has a mutant phenotype rather like that of $p i$ or ap 3 in Arabidopsis, and not at all like that of ag (Sommer $e t$ al. 1990). Thus, there are at least two cloned and sequenced plant homeotic genes that clearly encode related proteins. This raises hopes that others of the genes will be in the same gene family (Schwarz-Sommer et al. 1990). Indeed, preliminary screening of the Arabidopsis genome with the $D E F A$ cDNA clone has revealed a series of relatives, which seem to be more closely related to $D E F A$ than are any of the $A G$ relatives so far analyzed (T. Jack, L. L. Brockman and E. M. Meyerowitz, unpublished observations). In other words, the $A G / D E F$ gene family has an $A G$ and a $D E F$ subfamily, each with many members. We have started the RFLP mapping of members of both subfamilies, and there is evidence that one member of the DEF A subfamily maps very close to the $A P 3$ gene. The remarkable homology of homeotic genes of different function, from two widely diverged species, may therefore serve as a tool for the isolation of additional homeotic genes in both species.

\section{Unanswered questions}

Other than the apparent gaps, such as the still-uncloned homeotic genes, and the yet-to-be-performed molecular tests of the genetic model that will only be possible when the cloning of the other genes is complete, there are additional unanswered questions, for which new types of classical and molecular genetic experiments are required. These include questions about the exact cell types in which the homeotic genes act, and the degree to which they act autonomously in one cell layer and inductively on others. These also include aspects of the phenotypes of the homeotic genes not considered in the working model, such as the effects that some of these genes have on the formation and position of organ primordia, prior to their differentiation. There is also the key question of prepattern. Our model postulates that each of the homeotic genes comes to be expressed in a specific pattern, encompassing a field that comprises two adjacent whorls. While the patterns of eventual expression of $A G$ and $A P 2$ are to some degree dependent on an interaction between these genes, we do not know what their initial patterns of expression may be, since $A P 2$ is as yet uncloned, and our in situ hybridization experiments may be too insensitive to reveal the earliest expression of $A G$. We also do not know the mechanism by which $P I$ and $A P 3$ come to be expressed in the second and third whorls. Finally, there is another frontier: that of new, as yet undiscovered mutations. Though we have multiple alleles of each of the four homeotic genes, many other, undiscovered homeotic loci may exist. They may already be in our mutant collections, unrecognized, or they may have phenotypes in vegetative as well as floral cells, such that their floral phenotypes do not become apparent 
because of earlier lethal effects, or because flowers fail to form.

\section{Inductive interactions in organ development}

The inflorescence meristem and floral primordia of an Arabidopsis flowering stem contain two outer (tunica) layers, and internal cells. In other dicotyledonous plants where extensive mosaic studies have been done, it has been shown that each of these three sets of cells are, for the most part, clonally distinct throughout the development of the plant, and that each gives rise to different parts of each of the floral organs. Epidermal structures of flowers usually derive from the outer tunica layer (LI); the internal cells of sepals and petals, as well as some of the internal cells of stamens and ovaries (including the germ cells) derive from the second layer (LII); and the deepest cells in the sex organs usually derive from the inner cells (LIII) (Satina et al. 1940; Tilney-Basset, 1986). Since each floral organ derives from cells of different, clonally distinct, layers, and since all of the cells of each organ are of organspecific types (each Arabidopsis floral organ has its own distinguishable subtypes of epidermal and deeper cells: Pruitt et al. 1987; Hill and Lord, 1989; Smyth et al. 1990), each of these clonally distinct populations of cells must at some point learn its fate, and coordinate its development with that of the adjacent cell populations. Cells of each layer may either learn their fates independently, or the cells of the different layers may communicate, and the phenotypes of some cells result from inductive influences of adjacent cells. It has been known for over 70 years, from the study of genetic mosaics, that such induction does indeed occur. For example, an epidermis from a hairy tomato strain develops far fewer hairs than normal if it is growing over second layer cells derived from a hairless strain of nightshade (Krüger, 1931). A particularly apposite example from the old literature is Bateson's discussion of doubleness in chimeric Bouvardia (Bateson, 1916) ('double' is the horticultural term for mutations like agamous, which increase petal number, usually at the expense of stamens). He cites earlier examples where root cuttings from double Bouvardia plants grow up to give single (wild-type) flowers, implying that the original, double-flowered plants were genetic mosaics in which the clonally distinct layers were not all of the same genotype (since plants derived from root cuttings usually derive only from the inner layers). These results indicate that the absence of a wild-type flower-form gene in one or more outer cell layers was sufficient to make the entire flower mutant in phenotype. This demonstrates an inductive influence, of some sort, between the clonally-derived layers of the developing plant. Another example is that of 'Briarcliff roses, which have double flowers, but from which adventitious buds or root cuttings give rise to single flowers (Zimmerman and Hitchcock, 1951). This again shows that, at least in roses, mutations like agamous can have a direct effect in some cell layers, and an inductive effect in others. One of the most striking examples of a double flower mutation showing nonautonomous ex- pression is in a species chimera of a double (all stamens and carpels converted to petals) Camellia japonica and a wild-type Camellia sasanqua. In this case wild-type layer I cells, which develop into epidermal cells, direct underlying mutant LII and LIII derivatives to form stamens and carpels, even though these cells would never form these organs, or any of their specialized cell types, were they covered by an epidermis of their own genotype (Stewart et al. 1972; Stewart, 1978). Again, the phenotype of the flower seems to depend largely on the genotype of the epidermal cell layer. A final example of the determination of flower form by a single cell layer is the remarkable case of Antirrhinum majus wettsteinii. Antirrhinum flowers are normally bilaterally symmetrical. It appears from a considerable series of experiments that a radially symmetric flower (like that seen in cycloidea mutants) is due to a mutation only present in the LI layer, which gives rise to the epidermal cells of the flower. In these flowers a number of tests shows that the LII and LIII cells, which comprise the substance of most of the flower, and whose mutant phenotype is directed by the genotype of the epidermis, are genotypically normal (Melchers, 1960; Pohlheim, 1978).

The homeotic gene products in Arabidopsis (or any other plant) could thus determine organ type in at least two different fashions. They could act in cells derived from all of the layers of the flower primordium, or they could act autonomously in only a subset of the clonally distinct layers, and influence the differentiation of the other layers inductively. Only genetic mosaic experiments will tell us in which distinct layer of cells these genes have their primary effect, and which layers, if any, are affected secondarily. This sort of experiment will then reveal which of the homeotic phenotypes are due directly to loss of gene regulators, and which are due to loss of communication between cells which must communicate developmental information to each other. At this point it should be made explicit that $A G$ appears, from the in situ hybridization experiments, to express in cells derived from all three layers. Nonetheless, this is no guarantee that it acts in all three layers: even if it does, it could act quite differently in cells from each layer.

\section{Organ number and pattern}

The genetic model that we propose does a good job of predicting results in terms of organ type, but does not explain how the homeotic genes under study may regulate organ number, or the spatial patterns in which organ primordia appear. Two examples will suffice to show the failure of the model in this area. Our model predicts $A P 2$ activity to be critical for establishing organ type in whorls 1 and 2 only. There are no $A P 2$ effects on organ type in whorl 3 (unless $A G$ is also mutant). Nonetheless, ap2-2 and the other strong ap 2 mutants are missing most of their third whorl organs, and these organs can be abnormally positioned when they do appear. The strong ap2 mutants also lack some first and all second whorl organs (Komaki et al. 1988; Meyerowitz et al. 1989; Kunst et al. 1989; Bowman et al. 1991). 
The absence of these organs is due to failure of organ primordia ever to appear, and not to failure of initiated primordia to develop (Bowman et al. 1991).

Another example of the failure of our organ type model to treat organ number is the phenotype of the ag mutants. While the model explains the identity of organs in the first four whorls of these flowers (which may be considered equivalent to the four whorls of wild type, but are more reasonably considered whorls $1,2,3$ and then a repeat of whorl 1 , since the organ number and position in the fourth ag whorl is that of a wild-type whorl 1, not a wild-type whorl 4), the model does not address the indeterminacy of the mutant flowers: the existence of whorls 5,6,7 and so on. It is possible that the absence of organs in ap2 mutants is related to the antagonistic interaction of $A P 2$ and $A G$. One function of the wild-type $A G$ product is determinacy, that is, it causes cessation of organ formation in the center of the flower. The absence of $A P 2$ product in ap 2 mutants allows $A G$ to be expressed in whorls 1 and 2 , and at the same time prevents organ formation in these whorls. If the organ suppression in ap 2 mutants is indeed due to the ectopic expression of $A G$, the organs should be restored in double mutants of the genotype ap $2 \mathrm{ag}$. This is largely true: the double mutant has slightly less than the wild-type number of organs, but always has many more organs than ap2-2 single mutants (Bowman et al. 1991). This still does not explain the organ number effects of $a p 2$ in the third whorl, however, nor give a suitable mechanism for the $A G$ effect in the central part of developing flowers.

\section{Pattern establishment}

Another question that our model emphasizes, but does not answer, is that of the initial expression of the homeotic genes. For example, we postulate that $P I$ and $A P 3$ are active in only the second and third whorls, whether the other homeotic products are present or not. In addition, while the model suggests (and the molecular experiments demonstrate) that $A P 2$ and $A G$ interact in producing their final patterns of expression, the question of their initial patterns of expression remains. Since the phenotypic effects of ap 2 mutants (stage 2 in the system of Smyth et al. 1990) can be seen earlier in flower development than the initial expression of ag (stage 3), it seems clear that $A P 2$ expression precedes that of $A G$. Thus, the pattern of $A G$ expression may result entirely from a prepattern of $A P 2$ activity. It is not known how $A P 2$ comes to be active in only the outer whorls. While the homeotic genes control downstream genes, they are themselves under the control of yet other genes, which establish a prepattern to which the homeotic genes respond. There is thus a sequence of gene activities that control spatial patterning in flower development, and the homeotic genes act at only one time in the overall process of pattern formation.

We do not yet know which genes may regulate the pattern of homeotic gene expression, though we have candidate mutations whose phenotypes indicate the possibility that the wild-type function of the mutated genes may be in establishment of this pattern. One is the mutation superman-1, a third chromosome recessive mutation whose phenotype appears to be expansion of the third whorl at the expense of the fourth, and perhaps some expansion of the second whorl at the expense of the third (U. Mayer, G. Jürgens, D. Weigel, J. Bowman and E. Meyerowitz, unpublished data). The superman-1 mutants have normal numbers of sepals in the first whorl (4), and of petals in the second (4), but inside these can have additional petalloid sepals, and up to two (or more) whorls of six stamens. Some flowers have normal carpels in their center, though others have only rudimentary carpels, or no organs at all (Fig. 6). The phenotype is thus consistent with an alteration in the prepattern that regulates the initial expression of the homeotic genes $P I$ and $A P 3$, and perhaps $A P 2$ as well. Other explanations are also possible.

Another potential prepattern locus is $L E A F Y$ (Haughn and Somerville, 1988; D. Weigel and E. Meyerowitz, unpublished observations). There are eight characterized recessive alleles at this fifthchromosome locus, and their phenotypes cover a range of effects. In some, the transition from vegetative to inflorescence meristem is disrupted, such that the apical meristem produces new leaves (with attendant vegetative meristems) in the place of flowers. The mature plant is highly branched, and contains only leaves. Other alleles have a weaker effect: flowers do form, but all of the floral organs are phylloid, with the appearance, for the most part, of leaves or carpelloid leaves. This phenotype resembles that of the triply mutant strains described above, with one major difference: the pattern of organs in these flowers is spiral, not whorled. One can imagine, then, that $L E A F Y$ expression is a necessary precursor to the formation of the prepattern to which the homeotic genes respond, and in addition, that the formation of this prepattern is related to the process of floral induction by a common requirement for the $L E A F Y$ product. $L E A F Y$ is thus another mutation which may be involved in formation of the prepattern. There is little doubt that there are others to be discovered, as well, and that when the prepattern is better understood, the activity of the homeotic genes (and our model for it) will be viewed in a new light.

\section{New genes?}

One additional question raised by our model is that of undiscovered genes. A process as complex as pattern formation, even in organisms such as plants with their simple construction and limited numbers of cell types, must rely on far more regulatory genes than we have as yet discovered. This must indicate that other genes, with roles as critical as those incorporated in our model, have gone undiscovered. Although we have multiple alleles of those genes that we so far recognize as homeotic, this does not mean that the genome has been mutagenically saturated. Some may occur more rarely than those studied; others may have vegetative phenotypes in addition to those in the flower, and have consequently gone unrecognized; and yet others may have lethal phenotypes, so that only a screen for 
conditional mutations will reveal them. It seems clear that one frontier in the genetic study of flower development is the design of screens to identify such mutations.

\section{Conclusions}

By studying the phenotypes of a series of homeotic mutations, each of which affects flower development in the mustard Arabidopsis thaliana, we have derived a simple working model for the process by which groups of cells in the developing flower 'choose their fate'. The model is consistent with the phenotypes of the mutations, and correctly predicts the phenotypes of doubly and triply mutant strains. In addition, the molecular cloning of one of the Arabidopsis genes has allowed a series of molecular tests of the genetic model. The results of these tests are also consistent with the model, and confirm the hypothesis that the normal spatial pattern of expression of the AGAMOUS gene is partly a result of the activity of the APETALA2 gene. Despite these successes, the model does not explain how floral organs appear in appropriate positions and appropriate numbers; it only speaks to the specification of organ fate.

The fact that similar mutations to those described in Arabidopsis have been found in Antirrhinum, a plant in a distant family of dicots, indicates the possibility that the processes of flower development in all flowering plants are comparable (Coen and Carpenter, 1986; Meyerowitz et al. 1989; Sommer et al. 1990; Carpenter and Coen, 1990; Schwarz-Sommer et al. 1990). The molecular cloning of homeotic genes from both Arabidopsis and Antirrhinum, and the discovery that these genes are members of the same gene family, emphasizes this possibility. It also opens to experimental investigation the molecular basis of the evolutionary differences in organ form and pattern that are characteristics of flowers of different taxonomic groups. Continued investigation should thus lead not only to answers to the questions of pattern formation in development, but also to insights into the mechanisms of morphological evolution.

We would like to acknowledge the contributions of the former student and postdoctoral fellows in our lab who worked on the flower project: Hong Ma (now at Cold Spring Harbor Labs), Robert E. Pruitt (now at the University of Minnesota), Usha Vijayraghavan (now at the Indian Institute of Science, Bangalore) and Martin F. Yanofsky (now at the University of California, San Diego). Also David R. Smyth, of Monash University, Melbourne, who contributed to the project while here on sabbatical leave.

Our work on flower development is funded by U.S. National Science Foundation grant DCB-8703439, and by funds from the Lucille P. Markey Charitable Trust. J.L.B. and L.L.B. have been supported by NIH training grant 5T32GM07616; G.N.D. and T.P.J. are supported by NIH postdoctoral fellowships, L.E.S. is a fellow of the Damon Runyon-Walter Winchell Cancer Fund, and D.W. is an EMBO long-term fellow.

\section{References}

Bateson, W. (1916). Root cuttings, chimaeras and 'sports' J. Genet. 6, reprinted in Sctentific Papers of William Bateson, vol, II, 1928. Cambridge University Press: Cambridge.

Bernier, $G$ (1988). The control of floral evocation and morphogenesis. A. Rev Plant Physiol. Plant molec. Biol. 39. $175-219$.

Bowman, J. L., Smyth, D. R. and Meyerowitz, E. M. (1989). Genes directing flower development in Arabidopsis. Plant Cell 1, 37-52.

Bowman, J. L., Smyth, D. R. and Meyerowitz. E. M. (1991). Genetic interactions between the floral homeotic genes of Arabidopsis. Development 112, 1-19.

Boxer, L. M., Prywes, R.. Roeder, R. G. and Kedes, L. (1989). The sarcomeric actin CArG-binding factor is indistingushable from the c-fos serum response factor. Molec. cell Biol. 9. 515-522.

Braun, A. (1873). Ueber ein gefülltes und durchwachsenes Exemplar von Arabus Thahana. Sutzungs Gesell. Naturforsch. Freunde z. Berlin, 75.

Carpenter, R. and Coen. E. S. (1990). Floral homeotic mutitions produced by transposon mutagenesis in Antirrhinum majus. Genes Dev. 4, 1483-1493.

Chang, C., Bowman, J. L.. DeJohn. A W, Lander. E. S. and MEYEROWITZ, E M (1988). Restriction fragment length polymorphism linkage map for Arabidopsis thahana. Proc. natn. Acad. Sci. U.S.A. 85, 6856-6860.

Coen, E. S. and Carpenter, R. (1986). Transposable elements in Anturrhinum majus: generators of genetic diversity. Trends Genet 2, 292-296.

Feldmann, K. A., Marks, M. D., Christianson, M. L. and Quatrano, R. S. (1989). A dwarf mutant of Arabidopsis generated by T-DNA insertion mutagenesis. Science 243, $1351-1354$.

GoEbeL, K. (1900). Organography of Plants (translated by I. Balfour), Clarendon Press: Oxford

GREEN. P. B. (1988). A theory for inflorescence development and flower formation based on morphological and biophysical analysis in Echeveria. Planta 175, 153-169.

Haughn, G. W. and Somerville. C. R. (1988). Genetic control of morphogenesis in ArabidopsLS Dev Genet. 9, 73-89.

Herskowitz, I. (1990). A regulatory hierarchy for cell specialization in yeast. Nature $\mathbf{3 4 2} .749-757$

Heslop-Harrison, J. (1964). Sex expression in flowering plants. Brookhaven Symp. Biol 16, $109-125$.

Hill, J. P. AND LoRd, E. M. (1989). Floral development in Arabidopsis thaliana. a comparison of the wild type and the homeotic pistillata mutant. Can. J. Bot. 67. 2922-2936.

Jarvis, E. E., Clark, K. L. and Sprague, JR, G. F. (1989) The yeast transcription factor PRTF, a homolog of the mammalian serum response factor. is encoded by the MCMl gene. Genes Dev. 3, 936-945.

Komaki, M. K.. OKada. K., Nishino, E. and Shimura. Y. (1988), Isolation and characterization of novel mutants of Arabidopsis thaliana defective in flower development. Development 104, 195-203.

KOORNNEEF, M. (1989). Linkage map of Arabidopsis thatıana. In Genetic Maps, (5th edition). Cold Spring Harbor.

KRUGER, M (1931) Vergleıchend-entwicklungsgeschichte Untersuchungen an den Fruchtkoten und Früchten zweier Solanum-chimären und threr Elternarten. Planta 17, 372-436

Kunst, L., Klenz, J. E., Martinez-Zapater, J. and Haughn, G. W. (1989). AP2 gene determınes the identity of perianth organs in flowers of Arabidopsis thaliana. Plant Cell 1, 1195-1208.

Ma, H, Yanofsky, M. F. ANd Meyerowitz. E. M. (1991). $A G L 1-A G L 6$, an Arabidopsts gene family with similarity to floral homeotic and transcription factor genes. Genes Dev 5. 484-495.

Melchers, G. (1960). Haploide Blütenpflanzen als Material der Mutationszüchtung. Der Zuichter 30, 129-134.

MeyerowtTz, E. M. (1987). In situ hybridization to RNA in plant tissue. Plant Mol Bıol. Reporter 5, 242-250. 
Meyerowitz, E. M., Smyth, D. R. and Bowman, J. L. (1989). Abnormal flowers and pattern formation in floral development. Development 106, 209-217.

Norman, C., Runswick, M., Pollock, R. and Treisman, R. (1988). Isolation and properties of cDNA clones encoding SRF a transcription factor that binds to the c-fos serum response element. Cell 55, 989-1003.

Passmore, S., Elble, R. and Tye, B-K. (1989). A protein involved in minichromosome maintenance in yeast binds a transcriptional enhancer conserved in eukaryotes. Genes Dev 3 , 921-935.

Payer, J-B. (1857) Traite d'Organogenie Comparee des la Fleur. Masson: Paris.

Pohlheim, F. (1978). Untersuchungen an Antirrhinum majus wetsteinii, einer an vegetativ haploiden Pflanzen entstandenen Sproßvariante. Zbl. Biol. 97, 53-67.

Prumt, R. E., Chang, C., Pang, P. P. Y. and Meyerowitz, E. M. (1987). Molecular genetics and development of Arabidopsis. In Genetic Regulation of Development, (ed. W. R. Loomis), pp. 327-338. A. R. Liss Inc.: New York.

Satina, S., Blakeslee, A. F. and Avery, A. G. (1940). Demonstration of the three germ layers in the shoot apex of Datura by means of induced polyploidy in periclinal chimeras. Am. J. Bor. 27, 895-905.

SATTLER, R. (1973). Organogenesis of flowers: a photographic textarlas. Toronto.

Schwarz-Sommer, Z., Huluser, P., Nacken, W., Saedler, H. and
SOMmer, H. (1990). Genetic control of flower development by homeotic genes in Antirrhinum majus. Sctence 250, 931-936. Smyth, D. R., Bowman, J. L. and Meyerowttz, E. M. (1990). Early flower development in Arabidopsis. Plant Cell 2, 755-767. Sommer, H., Beltrán, J. P., Huljser, P., Pape, H., Lónnig, W. E., Saedler, H. and Schwarz-Sommer, Z. (1990), Deficiens, a homeotic gene involved in the control of flower morphogenesis in Anttrhinum majus: the protein shows homology to transcription factors. EMBO J. 9, 605-613.

STEWART, R. N. (1978). Ontogeny of the primary body in chimeral forms of higher plants. In The Clonal Basis of Development, (ed. S. Subtelny and I. Sussex). Academic Press: New York. Stewart, R. N., Meyer, F. G. and Derman, H. (1972). Camellia + 'Daisy Eagleson,' a graft chimera of Camellia sasanqua and C. japonica. Am. J. Bot. 59, 515-524.

Tilney-Basset, R. A. E. (1986). Plant Chimeras. E. Arnold: London.

voN Goethe, J. W. (1790). Versuch die Metamorphose der Pflanzen zu erklären. Ettinger, Gotha (translated by $A$. Arber (1946). Goethe's botany, Chron. Bot. 10, 63-126.

Yanofsky, M. F., Ma, H., Bowman, J. L., Drews, G. N., FeldmanN, K. A. and Meyerowttz, E. M. (1990). Agamous: an Arabidopsis gene whose product resembles transcription factors. Nature 346, 35-39.

Zimmermann, P. W. and Hitchcock, A. E. (1951). Rose 'sports' from adventitious buds. Contr. Boyce Thompson Inst. Pl. Res, $16,221-224$. 